\title{
A Hypersensitivity-Like Response to Meloidogyne graminicola in Rice (Oryza sativa)
}

\author{
Ngan Thi Phan, Dirk De Waele, Mathias Lorieux, Lizhong Xiong, and Stephane Bellafiore ${ }^{\dagger}$
}

First author: Laboratoire Mixte International (LMI) RICE2, Agriculture Genetics Institute (AGI), Hanoi, Vietnam, and IRD, CIRAD, University of Montpellier, IPME, Montpellier, France; second author: Laboratory of Tropical Crop Improvement, Department of Biosystems, Faculty of Bioscience Engineering, University of Leuven (KU Leuven), Willem De Croylaan 42, B-3001 Heverlee, Belgium; and Unit for Environmental Sciences and Management, North-West University, 56405, Private Bag X6001, 2520 Potchefstroom, South Africa; third author: Institut de recherche pour le développement (IRD), CIRAD, University of Montpellier, DIADE, Montpellier, France; fourth author: National Key Laboratory of Crop Genetic Improvement, Huazhong Agricultural University, 47895, Wuhan, Hubei, 430070, China; and fifth author: IRD, CIRAD, University of Montpellier, IPME, Montpellier, France; and LMI RICE2, AGI, Hanoi.

Accepted for publication 19 November 2017.

\begin{abstract}
Meloidogyne graminicola is a major plant-parasitic nematode affecting rice cultivation in Asia. Resistance to this nematode was found in the African rice genotypes Oryza glaberrima and O. longistaminata; however, due to interspecific hybrid sterility, the introgression of resistance genes in the widely consumed $O$. sativa varieties remains challenging. Recently, resistance was found in $O$. sativa and, here, we report for the first time the histological and genetic characterization of the resistance to $M$. graminicola in Zhonghua 11, an O. sativa variety. Bright-light microscopy and fluorescence observations of the root tissue of this variety revealed that the root cells surrounding the nematode displayed a hypersensitivity-like reaction with necrotic cells at early stages of infection when nematodes are migrating in the root's mesoderm. An accumulation of presumably phenolic

compounds in the nematodes' neighboring root cells was also observed. In addition, at a later stage of infection, not only were few feeding sites observed but also the giant cells were underdeveloped, underlining an incompatible interaction. Furthermore, we generated a hybrid $O$. sativa population by crossing Zhonghua 11 with the susceptible $O$. sativa variety IR64 in order to describe the genetic background of this resistance. Our data suggested that the resistance to $M$. graminicola infection was qualitative rather than quantitative and, therefore, major resistance genes must be involved in this infection process. The full characterization of the defense mechanism and the preliminary study of the genetic inheritance of novel sources of resistance to Meloidogyne spp. in rice constitute a major step toward their use in crop breeding.
\end{abstract}

Rice (Oryza sativa L.) is the most important cereal produced worldwide. As a staple food, its production is essential for food security in many countries, especially in Asia (Kyndt et al. 2014; Seck et al. 2012). In lowlands, where rice is cultivated under irrigation, root-lesion (family Pratylenchidae) and root-knot (Meloidogyne spp.) nematodes are considered to be the most important root plant-parasitic nematodes affecting rice production (Bridge et al. 2005; Nicol et al. 2011). In addition, Meloidogyne spp. are commonly found in upland rice (Villanueva et al. 1992), making this group damaging in all rice producing agroecosystems. Root-knot nematodes penetrate the root system, induce root galling, and hijack the plant's metabolism to their own benefit by the establishment of giant cells (Kyndt et al. 2014). As a consequence, they cause a general weakening of the rice plant that can result in substantial yield loss (Bridge et al. 2005; Mantelin et al. 2017; Win et al. 2015).

The rice root-knot nematode Meloidogyne graminicola Golden \& Birchfield has emerged as the most damaging rice root-knot nematode (De Waele and Elsen 2007; Mantelin et al. 2017). It has been found in every South Asian and Southeast Asian country surveyed thus far (Bellafiore et al. 2015; Jain et al. 2012). In these regions, although a high diversity of different $O$. sativa varieties are being cultivated, whether lowland or upland, all were shown to be

${ }^{\dagger}$ Corresponding author: S. Bellafiore; E-mail: stephane.bellafiore@ird.fr

Funding: This research was supported by IRD, CRP-Rice (CGIAR), and GRiSP (MENERGEP).

*The $e$-Xtra logo stands for "electronic extra" and indicates that two supplementary figures are published online.

(C) 2018 The American Phytopathological Society susceptible to M. graminicola infection (Cabasan 2015; Das et al. 2011; Padgham et al. 2004; Win et al. 2013). In an M. graminicolainfested rainfed lowland rice field in Bangladesh, nematicide application resulted in a yield increase of 16 to $20 \%$ or approximately 1 ton ha $^{-1}$ (Padgham et al. 2004). A similar observation was done in $M$. graminicola-infested upland rice fields in Thailand, where nematicide application resulted in a yield increase of 12 to $33 \%$ (Arayarungsarit 1987).

Crop rotation, flooding, and the use of nematicides are limited practices that are often used to manage plant-parasitic nematodes in infested rice fields. The effect of crop rotation has been reported to be partially efficient because of the wide host range of M. graminicola (Rahman 1990; Ventura et al. 1981). Flooding effectively inactivates or kills most soil nematodes but is not an option in areas where water scarcity is being experienced and increasing, such as in Asia (De Waele et al. 2013). Chemical soil sterilization is effective but expensive and environmentally harmful. Moreover, there have been few options proposed for chemical control of nematodes since the banishment of 1,2-di-bromo-3-chloropropane and ethylene di-bromide (MBTOC 2010), while more chemicals are being forbidden. In this context, the search for rice genotypes that are either resistant or tolerant to $M$. graminicola offers a valuable alternative to manage this important nematode species in rice production.

Natural resistance sources found in the rice germplasm offer one of the most promising and practical management alternatives to the use of chemicals. Resistance to M. graminicola has been identified in O. longistaminata and in African rice (O. glaberrima) (Plowright et al. 1999; Soriano et al. 1999), although M. graminicola has not yet been found on rice in Africa, except on the island of Madagascar (Chapuis et al. 2016). Unfortunately, introgressing this resistance into Asian rice (O. sativa) has not been very successful because the 
interspecific progenies do not express the same degree of resistance observed in O. glaberrima (Plowright et al. 1999; Soriano et al. 1999). Considerable efforts have been undertaken to identify resistance to $M$. graminicola infection in the abundant $O$. sativa germplasm but without much success (Bridge et al. 2005). Confirmed differences in host response to $M$. graminicola infection were observed in only a limited number of Asian rice genotypes (Bridge et al. 2005; Jena and Rao 1977; Prasad et al. 2006; Sharma-Poudyal et al. 2004).

Recent studies of resistant $O$. glaberrima genotypes have revealed three independent resistance mechanisms to $M$. graminicola infection in these genotypes (Cabasan et al. 2014). First, in resistant plants, infective second-stage juveniles (J2) of M. graminicola may penetrate the roots but, once inside, their development is delayed, resulting in limited reproduction (Cabasan et al. 2012). Second, an early hypersensitive response (HR)-like reaction was often observed, preventing giant cell formation and further development of the nematodes and, ultimately, resulting in nematode death (Cabasan et al. 2014; Goverse and Smant 2014; Kyndt et al. 2014; Petitot et al. 2017). Third, the degradation of the giant cells at late stages of infection by $M$. graminicola was considered as a late resistance response (Kyndt et al. 2014).

In the present study, we describe the mechanism of resistance to $M$. graminicola infection observed in Zhonghua 11, an $O$. sativa subsp. japonica variety. We further demonstrate by a genetic approach that the resistance genes can be used in breeding programs that aim to develop new resistant rice varieties suitable for lowland and upland rice-producing agroecosystems.

\section{MATERIALS AND METHODS}

In our study, the varieties Zhonghua 11 and $O$. sativa subsp. indica 'IR64' as well as their offspring ( $\mathrm{F}_{1}$ population) were included in the experiments. Zhonghua 11 originates from a rice-breeding program of the Chinese Academy of Agricultural Sciences and is commonly used in China as plant material to generate T-DNA mutant sources for research. Its seed were provided by L. Xiong (Huazhong Agricultural University) and its $F_{1}$ population was obtained from M. Lorieux, Institut de recherche pour le développement (IRD). IR64 was selected for our study because it is susceptible to $M$. graminicola infection (Cabasan et al. 2012). The M. graminicola population was isolated from a rice field in Laurel, Batangas, Philippines (Soriano et al. 1999). The population was established and multiplied from a single female on IR64 roots under hydroponic conditions (Hoagland and Arnon 1938) during 4 weeks before egg and J2 extraction. J2 were recovered from infected roots using a hypochlorite extraction method (Bellafiore et al. 2015; Besnard et al. 2014). Only J2 recovered from freshly hatched eggs were used as inoculum (i.e., less than $96 \mathrm{~h}$ after hatching).

Nematode reproduction. Seed from Zhonghua 11 and IR64 and their $\mathrm{F}_{1}$ progeny were germinated on sand wetted with a Hoagland $1 / 4$ solution $\left(5 \mathrm{mM} \mathrm{KNO}_{3}, 1 \mathrm{mM} \mathrm{KH}_{2} \mathrm{PO}_{4}, 5 \mathrm{mMCa}\left(\mathrm{NO}_{3}\right)_{2}\right.$, $2 \mathrm{mM} \mathrm{MgSO} 4,25 \mathrm{mg}$ of iron, and trace elements) (Hoagland and Arnon 1938). Seven days later, plantlets were transferred to tubes containing $10 \mathrm{~g}$ of sand and absorbent polymer (SAP) substrate (Reversat et al. 1999) wetted with the Hoagland 1/4 solution. Three days later, each plantlet was inoculated with $100 \mathrm{~J} 2$ by pipetting the nematode suspension around the stem's base. At 3 days postinoculation (DPI), plantlets were transferred to a 15-ml hydroponic culture system with Hoagland 1/4 solution (Hoagland and Arnon 1938). Plants were maintained in a climate-controlled room at a temperature regime of 26 and $24^{\circ} \mathrm{C}$ (day and night, respectively) and a light regime of 14 and $10 \mathrm{~h}$ (day and night, respectively) $(60 \mu \mathrm{mol}$ $\mathrm{m}^{-2} \mathrm{~s}^{-1}$ illumination) at $78 \%$ relative humidity. This experimental setup simulated lowland growing conditions. To simulate upland growing conditions, rice plantlets of Zhonghua 11 and IR64 and their $\mathrm{F}_{1}$ offspring were grown from seed directly planted in pots $(73 \mathrm{~mm}$ high and $50 \mathrm{~mm}$ in diameter) filled with an autoclaved mixture (1:1) of natural rice paddy soil (heavy soil) and sand (particle size of 0.1 to $0.4 \mathrm{~mm}$ ). Two weeks after seeding, each plantlet was not irrigated for 1 day before inoculation with $400 \mathrm{~J} 2$, as described above. Plants were watered every 3 days in order to conserve a nonsaturated soil (50\% of soil pore volume filled with water). The roots of the plants grown under simulated lowland conditions were collected at $25 \mathrm{DPI}$; for those grown under simulated upland conditions, the root systems were uprooted at 56 DPI. The roots were then carefully rinsed under tap water to remove the substrate. Root weight was measured before nematode extraction, as described previously (Bellafiore et al. 2015; Besnard et al. 2014). For each root system, the total numbers of eggs, $\mathrm{J} 2$, and males were recorded and the sum of eggs $+\mathrm{J} 2$ gave the final population density $(\mathrm{Pf})$. The reproductive factor $(\mathrm{RF})$ per gram of roots was calculated according to the following ratio: $\mathrm{RF}=\mathrm{Pf} /(\mathrm{Pi} \times$ root weight), where $\mathrm{Pi}=$ initial population. Ten replicate plants were examined for each rice genotype and the experiment was repeated twice.

Nematode penetration and development. For both Zhonghua 11 and IR64, the plantlets were grown and inoculated under the same conditions and methods as described above. After 3 days, the inoculated plants were transplanted to hydroponic conditions. At each time point $(1,2,3,4,7,10,14,18$, and $21 \mathrm{DPI})$, the infected roots from 10 plants of each variety were uprooted, carefully washed under tap water to remove the substrate, and stained with acid fuchsin (Byrd et al. 1983. The number of galls in the root systems were recorded, thus allowing calculation of the percentage of galls (number of galls/total number of roots) in each root system. The total number of roots corresponds to the sum of radicle roots (ra) and embryonic crown roots (ecr). We considered only these roots because they emerge just after germination (Rebouillat et al. 2009) when plants are grown in sand and, therefore, when J2 nematodes can potentially infect them. The ra as well as the first three ecr root tips of each plant were cut (approximately $2 \mathrm{~cm}$ from the root tip) and pressed between two glass slides in a drop of 50\% glycerol before examination using a stereomicroscope. The ra and ecr roots with nematodes inside their tissue were considered to be infected. The percentage of infected roots (ra or ecr cut and examined) was calculated for each plant and an average value of 10 plants was finally used for each time point and rice variety. This experiment was repeated twice.

Histopathology. Zhonghua 11 and IR64 as well as their $F_{1}$ offspring were grown and inoculated under the same conditions and methods as described above with additional noninoculated control plants. At each time point $(1,2,4,7,10,14,18$, and $21 \mathrm{DPI})$, five plantlets of the two varieties were uprooted and, at 7 DPI, five $F_{1}$ plantlets were uprooted. When visible, galls were excised with a scalpel; otherwise, the root tips (a 1-cm-long fragment of the ra and the three older ecr) of five plants of each genotype at each time point were excised using a stereomicroscope. Three root fragments of five noninoculated control plants were also collected. The excised root fragments were immediately placed in freshly prepared fixative buffer (PF) (2\% paraformaldehyde, 1\% glutaraldehyde, and $1 \%$ caffeine [Sigma-Aldrich] in $0.5 \times$ phosphate buffer, $\mathrm{pH} 7.2$ ) fixed for $48 \mathrm{~h}$ at $4^{\circ} \mathrm{C}$ in $\mathrm{PF}$ on a rocking plate under gentle agitation, before dehydration during $1 \mathrm{~h}$ in each ethanol dilution (twice at $50 \%$, twice at $70 \%$, twice at $95 \%$, and once at $100 \%$ [vol $/ \mathrm{vol}])$ and embedded in the epoxy resin Technovit 7100 (Kulzer Friedrichsdorf) according to Pegard et al. (2005). Serial longitudinal and cross-sections were cut $(5 \mu \mathrm{m})$ with a Thermo Scientific HM340E rotary microtome and observed using a stereomicroscope under UV light (UV filter set A2; Zeiss AXIO Imager) to detect yellow and orange autofluorescence indicating the presence of phenolic compounds (Pegard et al. 2005). The same sections were subsequently stained ( $3 \mathrm{~min}$ at room temperature) with $0.05 \%$ toluidine blue in $0.1 \mathrm{M}$ sodium phosphate buffer, $\mathrm{pH} \mathrm{6.5,} \mathrm{and} \mathrm{mounted} \mathrm{in} \mathrm{Neo-Mount} \mathrm{(Merck-}$ Millipore) according to the manufacturer's recommendations. Images were taken with a Q-imaging digital camera mounted on an Olympus BX50 stereomicroscope with standard bright-field optics. 
To study giant cell formation, microscopic measurements were performed on a cross section of each root segment at its point of maximum root gall expansion according to Vovlas et al. (2005). The following variables were determined: (i) number of feeding sites per gall, (ii) number of giant cells per feeding site, and (iii) area of each giant cell in the feeding site. The measurements were made with ImageJ software (Rasband 2014) (https://imagej.nih.gov/ij/).

Statistical analysis. Statistical analyses were performed using R software (R Development Core Team 2009) (https://www.rproject.org/). The numeric data of two replications was subjected to analysis of variance to test for consistency. The mean value was calculated from two replications and was used to test for mean comparison between resistant and susceptible cultivars using the Tukey's honestly significant difference test. Statistical significant differences were accepted on the $95 \%$ significance level $(P<0.05)$.

\section{RESULTS}

Reproduction of $M$. graminicola on the $O$. sativa varieties IR64 and Zhonghua 11 and their $F_{1}$ offspring. The RF of M. graminicola on IR64 and Zhonghua 11 and on their $\mathrm{F}_{1}$ offspring showed a similar pattern under both lowland and upland simulated conditions (Fig. 1). As expected, nematodes massively reproduced on IR64, the susceptible reference genotype, with RF values of approximately 200 in both growing conditions. In contrast, significantly $(P<0.001)$ low RF values were observed on Zhonghua 11 and $F_{1}$ plants. On Zhonghua 11 , the $R F$ was $<1(R F=0.9$ and 0.15 on upland and lowland simulated conditions, respectively), indicating that nematodes failed to reproduce on this rice variety. The same level of resistance $(P<0.01)$ to $M$. graminicola infection with Zhonghua 11 was observed on the $\mathrm{F}_{1}$ plants under both simulations for lowland $(\mathrm{RF}=2.5)$ and upland $(\mathrm{RF}=1.74)$ conditions.

Penetration and development of $M$. graminicola on Zhonghua 11 and IR64. The penetration and development of J2 on Zhonghua 11 and IR64 are shown in Supplementary Figure S1. At 1 DPI, J2 were found near the root tips of the root system in both Zhonghua 11 and IR64. Later, J2 concentrated in the root tips of IR64 at 2 DPI and Zhonghua 11 at 3 DPI. In Zhonghua 11, only slight root galling was observed at 7 DPI whereas, in IR64, root galling was observed already at 2 DPI (Supplementary Fig. S2). Many female nematodes presenting a typical pear shape and a massive amount of eggs were found inside the IR64 roots at 14 DPI. Meanwhile, in Zhonghua 11, only one or two nematodes were observed in the root system after 10 days of infection. Only a few nematodes with a round shape and their first few eggs were observed in the root system of Zhonghua 11 at 18 DPI.

In Zhonghua 11, an average of five $\mathrm{J} 2$ having successfully penetrated per root was found at 1 DPI (Fig. 2A). During the following days of infection, more than $85 \%$ of the $\mathrm{J} 2$ that had penetrated the roots had disappeared from the root system of Zhonghua 11 and one or no nematodes per root remained on the final day. In IR64, three to four J2 were found per root at 1 DPI; however, during the first 3 days on SAP, the number of nematodes increased significantly, peaking at 3 DPI (seven nematodes per root), then maintaining its population density under hydroponic conditions. At 10 DPI, the number of J2 per root of IR64 could not be determined because too many eggs and female nematodes were found in the galls of the root systems (Fig. 2A).

During the early stages of infection, the root systems of both Zhonghua 11 and IR64 were infected by M. graminicola at approximately the same level (60 to $70 \%, P<0.01)$ (Fig. 2B). However, whereas IR64's root systems remained infected (70 to $80 \%, P<0.01)$ throughout the period of observation, the percentage of infected root in the root system of Zhonghua 11 decreased to $<30 \%(P<0.01)$ at $21 \mathrm{DPI}$. A similar pattern was observed in the ra and in the infected ecr (Fig. 2C and D): in IR64, 90 to $100 \%(P<$ $0.01)$ of the ra roots were infected and stayed so until 21 DPI whereas, in Zhonghua 11, 80 to $90 \%(P<0.01)$ of the ra roots were again infected in the first 3 days but only $40 \%$ remained infected at 21 DPI. Consistent with the number of nematodes per root, the percentage of infected embryo crown roots in IR64 increased from 51 to $64 \%(P<0.01)$ during the time that the rice plants were on SAP before a stable level of $70 \%(P<0.01)$ at 21 DPI. Once again, a significant decrease of infected embryo crown roots was shown in Zhonghua 11 from 1 DPI $(61 \%, P<0.01)$ till the end of the infection stage at $21 \mathrm{DPI}(24 \%, P<0.01)$.

Histopathology observation of $M$. graminicola on IR64 and Zhonghua 11 and their $F_{1}$ offspring. Microscopic observations under UV excitation and toluidine coloration of root sections of both IR64 and Zhonghua 11 at 1 DPI showed that J2 had reached the cortex layer of the roots and had migrated intercellularly (Fig. 3A). The root sections of Zhonghua 11 under UV excitation showed yellow or orange autofluorescence, indicating the presence of aromatic compounds, in the cytoplasm and in the cell walls of the cell layer surrounding the nematodes immediately at 1 and 2 DPI. Examination of these root sections by toluidine blue staining also showed the blue-green color corresponding with yellow or orange autofluorescence under UV excitation. This confirmed the presence of aromatic compound accumulation in cells neighboring the nematodes or potentially targeted by the nematodes to transform them into feeding sites. At 7 DPI, plant cells surrounding the nematodes in root sections of Zhonghua 11 presented abnormal structures and accumulated aromatic compounds, as revealed by autofluorescence under UV excitation that was consistent with blue-green color after coloration with toluidine blue (Fig. 3B). At $10 \mathrm{DPI}$, the first giant cells and feeding sites, both responsible for the root galling phenotype, were found in root sections of Zhonghua 11
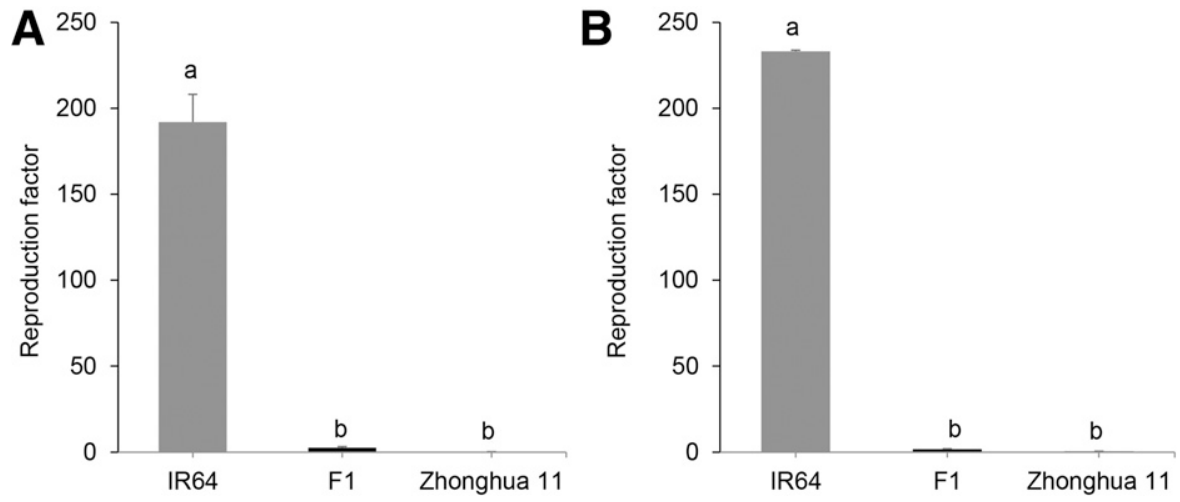

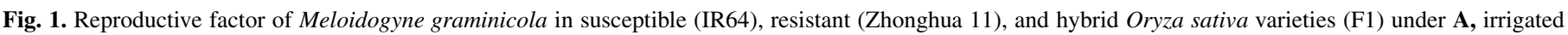

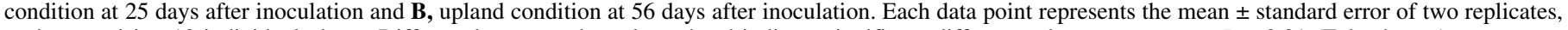
each comprising 10 individual plants. Different letters on the column head indicate significant differences between mean at $P<0.01$ (Tukey's test). 
and were surrounded by intense yellow fluorescence (under UV light) and blue-green color (after coloration) (data not shown). In IR64, the first giant cells already appeared in root sections as of 2 or 3 DPI (data not shown) and neither yellow autofluorescence nor blue-green color was observed in the cells surrounding the nematodes at 1 and 7 DPI, suggesting the absence of the aromatic compound accumulation (Fig. 3A and B). Finally, at 21 DPI, some nematodes were still moving inside the root system of Zhonghua 11 but they didn't present the pear-shaped characteristic of the nematode female at adult stage; whereas, in IR64, nematodes had established their feeding sites since 4 DPI (data not shown).

Similar observations were found in $\mathrm{F}_{1}$ plants' root tissues from Zhonghua 11 at 7 DPI (Fig. 3B). At the same time point, the cell layers surrounding the nematodes presented messy arrangements and aromatic compounds within their cytoplasm and cell walls and only a few of the $\mathrm{J} 2$ had initiated a feeding site, where a strong signal of aromatic compounds was then found in the neighboring cells.

Root galling, feeding sites, and morphology of giant cells. Root galling was mainly observed in the root tips in IR64 whereas, in Zhonghua 11, it appeared in both root tips and secondary root meristems. During infection, the root system of Zhonghua 11 presented $<20 \%$ of galls induced by nematodes whereas a high rate of $>70 \%$ of root galling was observed in IR64. Moreover, a significant lower number of feeding sites (only one or two per gall) was observed in the infected root galls of Zhonghua 11 in comparison with those of IR64 (Fig. 4A). This was consistent with our previous experiment, where we found less than one nematode per root in the late stages of infection (Fig. 2A). The number of giant cells in each feeding site was equal (average of five giant cells per feeding site) in both varieties (Fig. 4B). Well-formed giant cells with uniformly dense cytoplasm and numerous small nuclei were observed in root sections of IR64 whereas, in Zhonghua 11, smaller cells with thinner cell walls were found (Fig. 3B). Finally, the mean area of the giant cells induced by nematodes in Zhonghua 11 was half that in IR64 (Fig. 4C).

\section{DISCUSSION}

Our study showed a high level of penetration into the roots by M. graminicola $\mathrm{J} 2$ in both Zhonghua 11 and IR64 at the early stages of infection but the number of $\mathrm{J} 2$ that had penetrated declined rapidly in Zhonghua 11 within the following days. A similar mode of decline has already been described in tobacco resistant to M. incognita infection (Schneider 1991). In contrast, a low penetration level was commonly observed in several resistant plantnematode interactions such as between coffee and $M$. exigua (Anthony et al. 2005), pepper and M. incognita (Bleve-Zacheo et al. 1998), grape and M. arenaria (Anwar and McKenry 2002), and peanut and M. arenaria (Bendezu and Starr 2003). Differences in penetration of nematodes among plant species could be explained by the differences in the root features, including root morphology (root weight, number of lateral roots, and root hair) (Cabasan et al. 2014; Jena and Rao 1977), root anatomy at the cellular level (stele diameter, cortex thickness, xylem vessel diameter, and epidermal thickness) (Huang 1985), and biochemical barriers (Pegard et al. 2005). Some of these features are related to the defense mechanisms which pre-existed or induced the formation of epidermal barriers or secretions of biochemicals to inhibit nematode infection (Huang 1985; Pegard et al. 2005). In our study, a massive penetration of M. graminicola J2 occurred in Zhonghua 11 in contrast with $O$. glaberrima resistant rice genotypes cited in Cabasan et al. (2012), indicating that Zhonghua 11 doesn't display prepenetration resistance. However, the rapid decrease of the nematodes in its roots suggests that host defense responses killed the nematodes or caused them to exit the roots. In addition, the delay of gall formation as well as nematode reproduction in Zhonghua 11 suggests the presence of defense reactions which inhibit nematode development and, therefore, limit giant cell formation. Inhibition of the development of $M$. graminicola was also observed in previous studies of other resistant rice genotypes, including O. glaberima (Cabasan et al. 2012; Jena and Rao 1977; Plowright et al. 1999; Yik and Birchfield 1979),
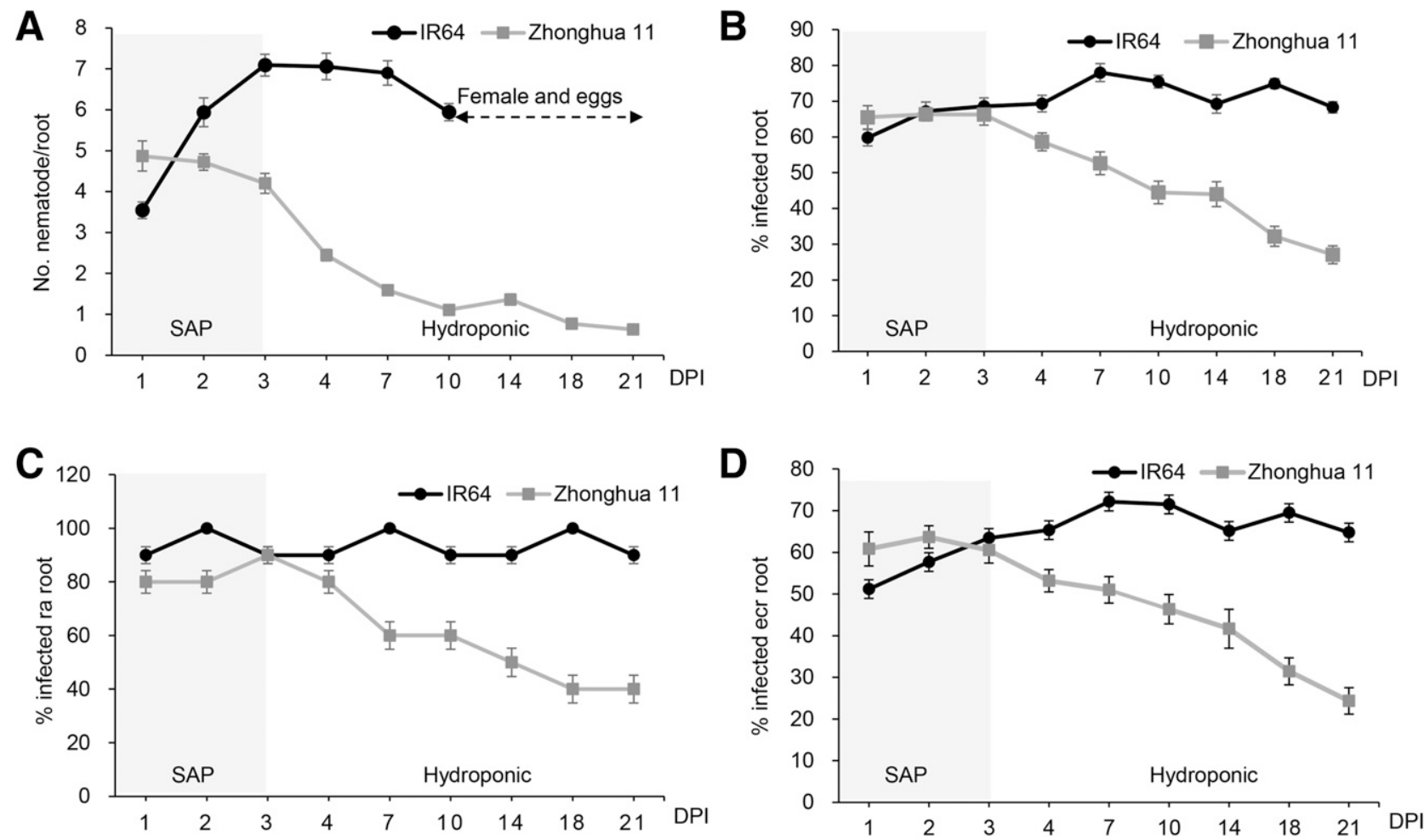

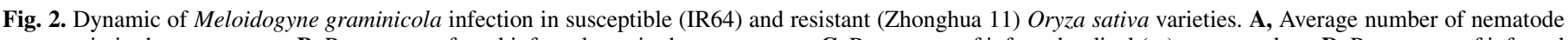

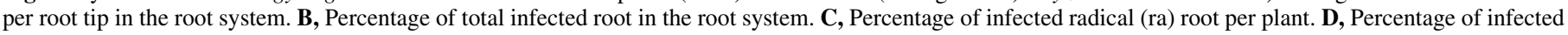

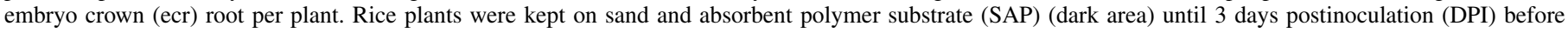

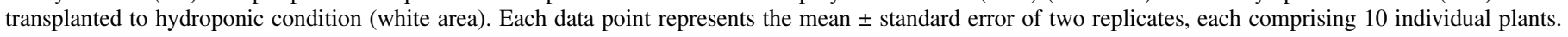


O. longistaminata (Soriano et al. 1999), and O. sativa (Dimkpa et al. 2016).

Development and reproduction of $M$. graminicola in the roots of IR64 were observed under both flooded and nonflooded conditions. In contrast, in Zhonghua 11, the significant low RF of M. graminicola indicated sustainable resistance under both simulated conditions. The mechanism of resistance to $M$. graminicola in Zhonghua 11 was inherited by some of the $F_{1}$ progenies, suggesting that resistance is conferred by dominant genes. Dominant inheritance of resistance to nematodes has been described in many crop species and for various Meloidogyne spp. such as M. incognita (Cap et al. 1993; Hare 1957; Slana and Stavely 1981; Yoshida 1981), M. javanica (Omwega and
Roberts 1992), M. hapla (Adamson et al. 1974), and M. arenaria (Esmenjaud et al. 1996). However, recessive inheritance for resistance to root-knot nematodes has also been suggested (Gentile et al. 1962; Struble et al. 1966; Wang et al. 2004). Most of the previous studies have focused on inheritance of root-knot nematode resistance in plants dealing with $M$. incognita; only some have been done with other Meloidogyne spp.; and, thus far, no description of the inheritance for resistance to $M$. graminicola has been published. Final conclusions about the dominant expression of resistance to $M$. graminicola infection in Zhonghua 11 are under study and must wait for results from evaluations of the $F_{2}$ and $F_{3}$ progenies.
A

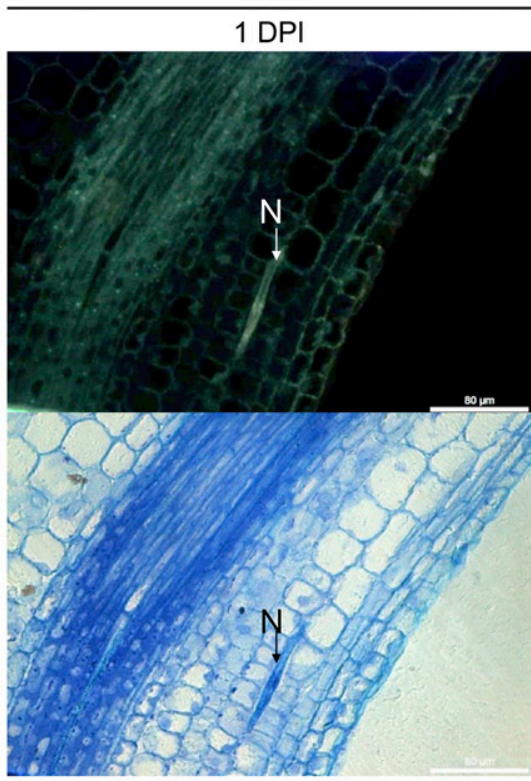

B

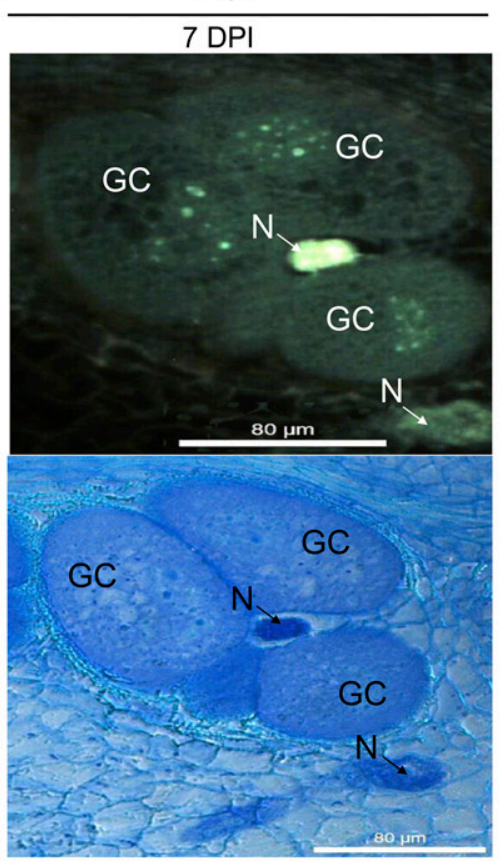

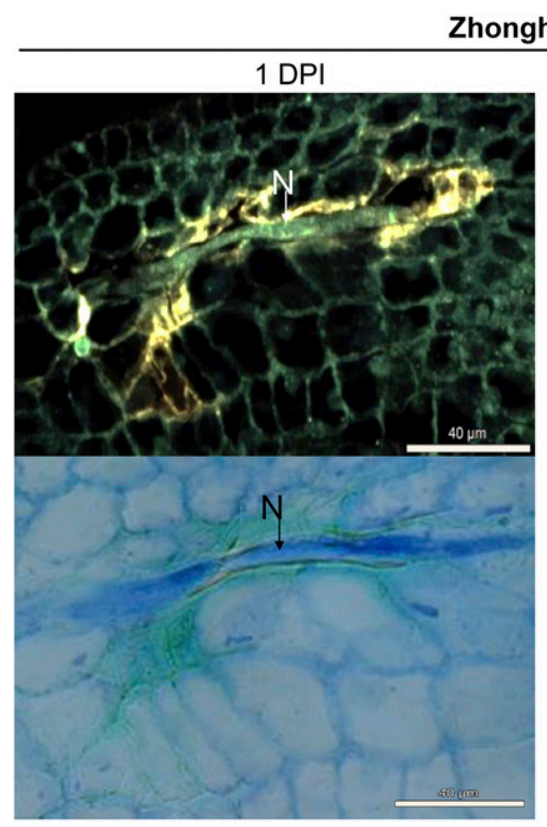

Zhonghua 11

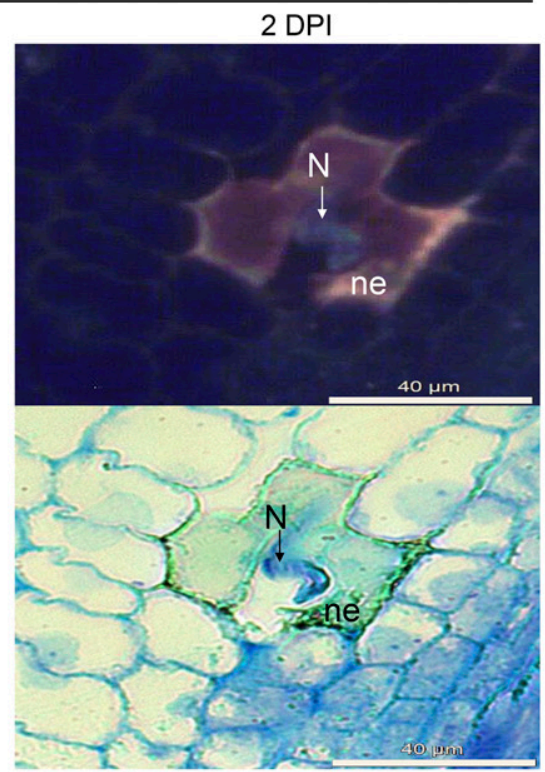

Zhonghua 11

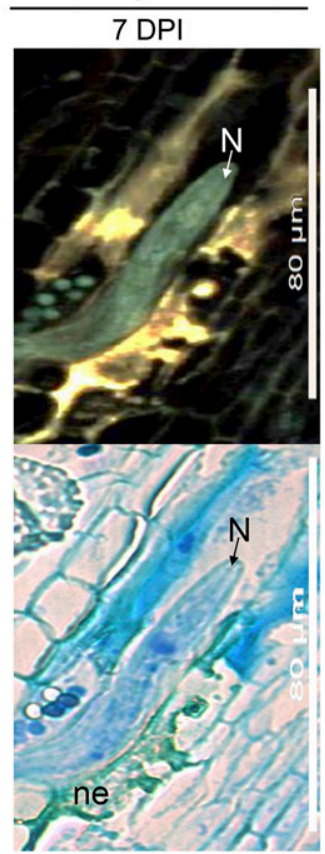

F1
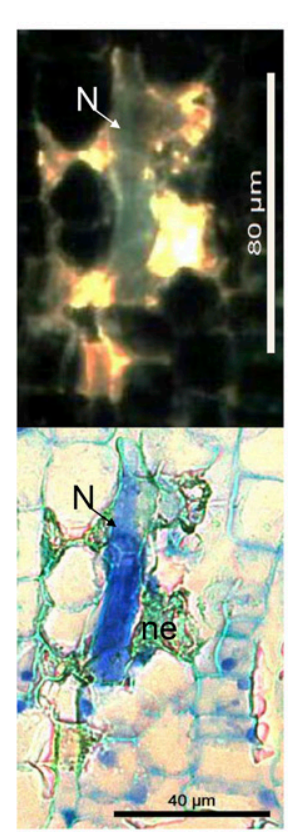

$7 \mathrm{DPl}$

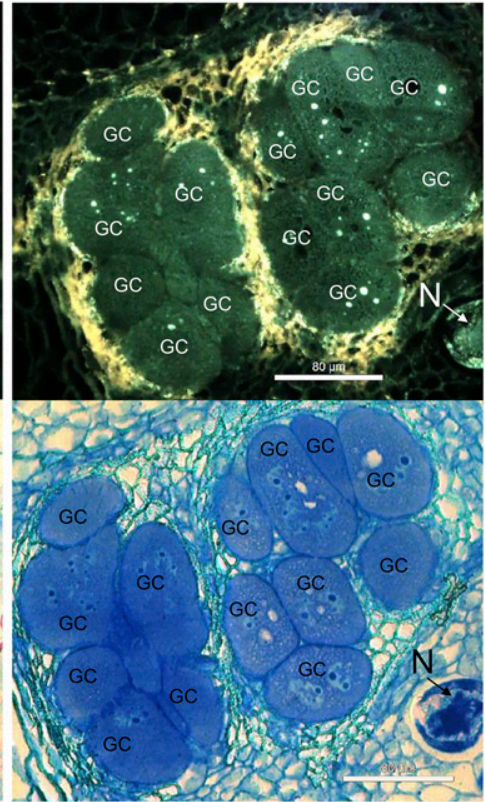

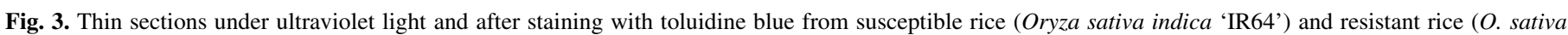

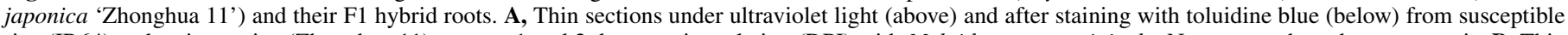

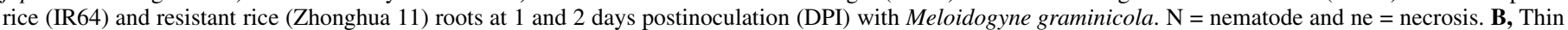

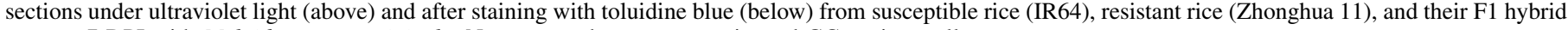
roots at 7 DPI with Meloidogyne graminicola. $\mathrm{N}=$ nematode, ne = necrosis, and GC = giant cell. 
Our histological study illustrates the resistance to $M$. graminicola infection in Zhonghua 11 and suggests that the resistance is related to an HR-like reaction. At 1 DPI, a blue-green coloration of material surrounding the nematode in its roots was obtained with toluidine blue staining. This observation suggests the immediate accumulation of aromatic compounds around the nematodes. A similar coloration was observed in $O$. glaberrima genotypes resistant to M. graminicola infection (Cabasan et al. 2014) and in coffee plants resistant to M. exigua (Silva et al. 2013). The presence of aromatic compounds surrounding the nematodes in the root sections of Zhonghua 11 was confirmed by the autofluorescence observation. Previous studies of the root tissues of prunus and pepper resistant to Meloidogyne spp. proved that the strong signal of yellow-orange fluorescence indicated the presence of high contents of aromatic compounds such as chlorogenic acid (Khallouk et al. 2011; Pegard et al. 2005). Aromatic compounds have also been shown to be associated with the active defense against plant-parasitic nematode infection (Bajaj and Mahajan 1977; Ohri and Pannu 2010). Our study shows that, in Zhonghua 11 at 2 DPI, the cells surrounding the nematodes presented not only yellow-orange autofluorescence under UV excitation but also blue-green coloration in the cytoplasm and cell wall after toluidine blue staining, thus maybe indicating an $\mathrm{HR}$-like reaction. An HR-like reaction after infection with root-knot nematodes has been observed in other cereals such as oat and barley (Baihadere and Evans 1995; Siddiqui 1971). Jena and Rao (1977) also observed cell necrosis in the cortex near the head of J2, thus preventing contact with the neighboring cells and inhibiting the establishment of feeding sites. The HR-like reaction inhibited J2 from feeding on the nutrients, thus affecting their fitness, which subsequently resulted in the death of nematodes or their banishment from the root system. This defense reaction was also observed during the migration of $\mathrm{J} 2$ in Zhonghua 11; nematodes were inhibited and only a few reached the globose stage (pear-shaped females), thus causing the extension of the migration phase in the cortex layer of the roots during the period of infection.

Despite HR-like reaction and aromatic compound accumulation in Zhonghua 11 at the late stages of infection, a small number of nematodes were still present and able to establish feeding sites leading to gall formation. However, their giant cells were poorly developed, with a small size and a thin cell wall, suggesting an upload of hydrolases and toxins into the vacuoles and a calcium flux in the cytoplasm that would deprive the nematodes of nutrients, leading to cell wall thinning and giant cell collapse (Das et al. 2008; Jones 2001). In Arabidopsis thaliana, downregulation of the gene CCS52 and overexpression of DEL1 prevented the formation of large polyploid nuclei and resulted in smaller feeding cells induced by M. incognita and Heterodera schachtii (de Almeida Engler et al. 2012). The depression of nematode fitness due to HR-like reaction could affect the induction of giant cells.

In conclusion, our results suggest that the $O$. sativa varieties resistant to $M$. graminicola display a postpenetration resistance mechanism at the tissue level: an early HR-like reaction defense response suppresses the nematode development and causes its death. In the view of our first results, this defense response is likely to be controlled by dominant genes. Moreover, the $O$. sativa resistant variety Zhonghua 11 expresses sustainable resistance to $M$. graminicola under flooded and nonflooded growing conditions. Our study provides a better understanding of resistant mechanisms of $O$. sativa rice genotype dealing with root-knot nematode $M$. graminicola and the desired features of resistance elucidated in this study could be potential sources for future breeding programs.
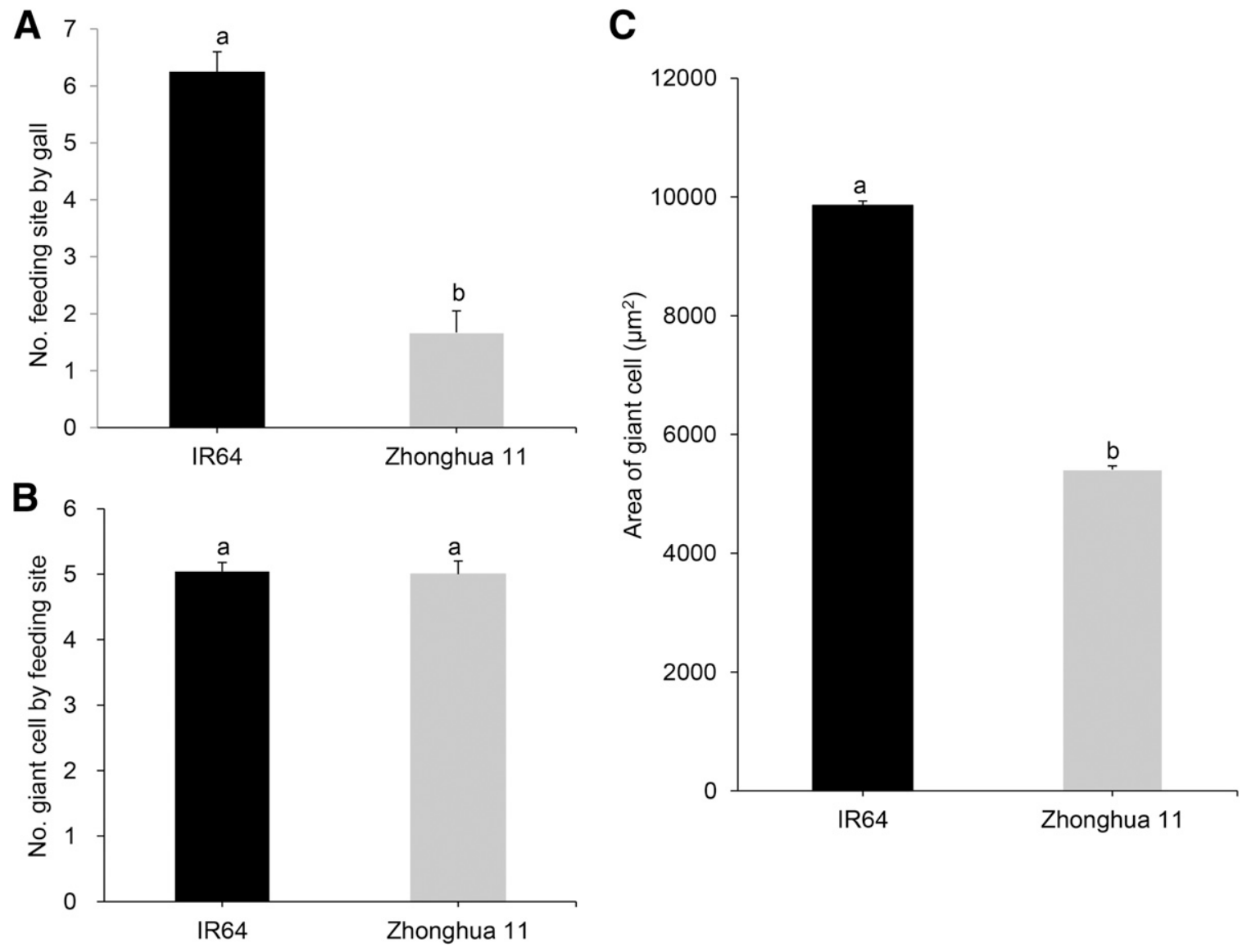

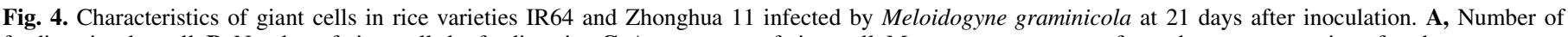

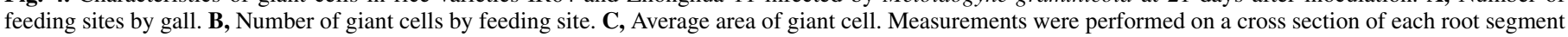

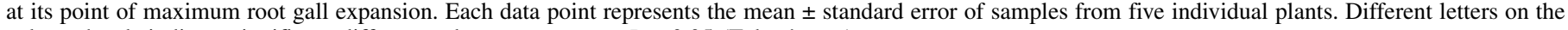
column heads indicate significant differences between mean at $P<0.05$ (Tukey's test). 


\section{ACKNOWLEDGMENTS}

We thank the International Join laboratory in Vietnam (LMI-RICE2) for the equipment and facilities, J. Aribi (IRD) for plant maintenance and technical assistance, and S. Maurice and L. Maurice for critical reading of the manuscript.

\section{LITERATURE CITED}

Adamson, W. C., Donnelly, E. D., Minton, N. A., and Miller, J. D. 1974. Inheritance of resistance to Meloidogyne hapla in Lespedezacuneata. J. Hered. 65:365-368.

Anthony, F., Topart, P., Martinez, A., Silva, M., and Nicole, M. 2005. Hypersensitive-like reaction conferred by the $M e x-1$ resistance gene against Meloidogyne exigua in coffee. Plant Pathol. 54:476-482.

Anwar, S. A., and McKenry, M. V. 2002. Penetration and development of Meloidogyne arenaria on two grape rootstocks. J. Nematol. 34:143-145.

Arayarungsarit, L. 1987. Yield ability of rice varieties in fields infested with the root-knot nematode. Int. Rice Res. Notes 12:14.

Baihadere, P., and Evans, A. A. 1995. Histopathogenesis of susceptible and resistant responses of wheat, barley and wild grasses to Meloidogyne naasi. Fundam. Appl. Nematol. 18:531-538.

Bajaj, K. L., and Mahajan, R. 1977. Phenolic compounds in tomato susceptible and resistant to $M$. incognita (Kofoid et White) Chitwood. Nematol. Mediterr. 5:329-333.

Bellafiore, S., Jougla, C., Chapuis, E., Besnard, G., Suong, M., Vu, P. N., De Waele, D., Gantet, P., and Ngo, X. T. 2015. Intraspecific variability of the facultative meiotic parthenogenetic root-knot nematode (Meloidogyne graminicola) from rice fields in Vietnam. C. R. Biol. 338:471-483.

Bendezu, I. F., and Starr, J. L. 2003. Mechanism of resistance to Meloidogyne arenaria in the peanut cultivar COAN. J. Nematol. 35:115-118.

Besnard, G., Juhling, F., Chapuis, E., Zedane, L., Lhuillier, E., Mateille, T., and Bellafiore, S. 2014. Fast assembly of the mitochondrial genome of a plant parasitic nematode (Meloidogyne graminicola) using next generation sequencing. C. R. Biol. 337:295-301.

Bleve-Zacheo, T., Bongiovanni, M., Melillo, M. T., and Castagnone-Sereno, P. 1998. The pepper resistance genes $\mathrm{Mel}$ and $\mathrm{Me} 3$ induce differential penetration rates and temporal sequences of root cell ultrastructure changes upon nematode infection. Plant Sci. 133:79-90.

Bridge, J., Plowright, R. A., and Peng, D. 2005. Nematode Parasites of Rice. CABI Publishing, Wallingford, UK.

Byrd, D. W. J., Kirkpatrick, T., and Barker, K. R. 1983. An improved technique for clearing and staining tissues for detection of nematodes. $J$. Nematol. 15:142-143.

Cabasan, M. T. N. 2015. A Study of the Resistance and Tolerance of African and Asian Rice Genotypes to the Rice Root-Knot Nematode Meloidogyne graminicola. Golden \& Birchfield, KU Leuven, Leuven, Belgium.

Cabasan, M. T. N., Kumar, A., and De Waele, D. 2012. Comparison of migration, penetration, development and reproduction of Meloidogyne graminicola on susceptible and resistant rice genotypes. Nematology 14: 405-415

Cabasan, M. T. N., Kumar, A., Bellafiore, S., and De Waele, D. 2014. Histopathology of the rice root-knot nematode, Meloidogyne graminicola, on Oryza sativa and $O$. glaberrima. Nematology 16:73-81.

Cap, G. B., Roberts, P. A., and Thomason, I. J. 1993. Inheritance of heat-stable resistance to Meloidogyne incognita in Lycopersicon peruvianum and its relationship to the $M i$ gene. Theor. Appl. Genet. 85:777-783.

Chapuis, E., Besnard, G., Andrianasetra, S., Rakotomalala, M., Nguyen, H. T., and Bellafiore, S. 2016. First report of the root-knot nematode (Meloidogyne graminicola) in Madagascar rice fields. Australas. Plant Dis. Notes 11:32.

Das, K., Zhao, D., De Waele, D., Tiwari, R. K. S., Shrivastava, D. K., and Kumar, A. 2011. Reactions of traditional upland and aerobic rice genotypes to rice root knot nematode (Meloidogyne graminicola). J. Plant Breed. Crop Sci. 3:131-137.

Das, S., DeMason, D. A., Ehlers, J. D., Close, T. J., and Roberts, P. A. 2008. Histological characterization of root-knot nematode resistance in cowpea and its relation to reactive oxygen species modulation. J. Exp. Bot. 59: 1305-1313.

de Almeida Engler, J., Kyndt, T., Vieira, P., Van Cappelle, E., Boudolf, V., Sanchez, V., Escobar, C., De Veylder, L., Engler, G., Abad, P., and Gheysen, G. 2012. CCS52 and DEL1 genes are key components of the endocycle in nematode-induced feeding sites. Plant J. 72:185-198.

De Waele, D., Das, K., Zhao, D., Tiwari, R. K. S., Shrivastava, D. K., Vera-Cruz, C., and Kumar, A. 2013. Host response of rice genotypes to the rice root-knot nematode (Meloidogyne graminicola) under aerobic soil conditions. Arch. Phytopathol. Plant Prot. 46:670-681.

De Waele, D., and Elsen, A. 2007. Challenges in tropical plant nematology. Annu. Rev. Phytopathol. 45:457-485.
Dimkpa, S. O., Lahari, Z., Shrestha, R., Douglas, A., Gheysen, G., and Price, A. H. 2016. A genome-wide association study of a global rice panel reveals resistance in Oryza sativa to root-knot nematodes. J. Exp. Bot. 67: 1191-1200.

Esmenjaud, D., Minot, J. C., Voisin, R., Bonnet, A., and Salesses, G. 1996. Inheritance of resistance to the root-knot nematode Meloidogyne arenaria in Myrobalan plum. Theor. Appl. Genet. 92:873-879.

Gentile, A. G., Kimble, K. A., and Hanna, G. C. 1962. Reactions of sweet potato breeding lines to Meloidogyne species when inoculated by an improved method. Phytopathology 52:1225-1226.

Goverse, A., and Smant, G. 2014. The activation and suppression of plant innate immunity by parasitic nematodes. Annu. Rev. Phytopathol. 52:243-265.

Hare, W. W. 1957. Inheritance of resistance to root knot nematodes in pepper. Phytopathology 47:455-459.

Hoagland, D. R., and Arnon, D. I. 1938. The water-culture method for growing plants without soil. Univ. Calif. Coll. Agric. Agric. Exp. Stn. Berkeley.

Huang, J. S. 1985. Mechanisms of Resistance to Root-Knot Nematodes. North Carolina State University Graphics, Raleigh.

Jain, R. K., Khan, M. R., and Kumar, V. 2012. Rice root-knot nematode (Meloidogyne graminicola) infestation in rice. Arch. Phytopathol. Plant Prot. 45:635-645.

Jena, R. N., and Rao, Y. S. 1977. Nature of resistance in rice (Oryza sativa L) to the root-knot nematode (Meloidogyne graminicola Golden and Birchfield). I. Histopathology of nematode infection in rice varieties. Proc. Indian Acad. Sci. 86:87-91.

Jones, A. 2001. Programmed cell death in development and defence. Plant Physiol. 125:94-97.

Khallouk, S., Voisin, R., Van Ghelder, C., Engler, G., Amiri, S., and Esmenjaud, D. 2011. Histological mechanisms of the resistance conferred by the Ma gene against Meloidogyne incognita in Prunus spp. Phytopathology 101:945-951.

Kyndt, T., Fernandez, D., and Gheysen, G. 2014. Plant-parasitic nematode infections in rice: Molecular and cellular insights. Annu. Rev. Phytopathol. 52:135-153.

Mantelin, S., Bellafiore, S., and Kyndt, T. 2017. Meloidogyne graminicola: A major threat to rice agriculture. Mol. Plant Pathol. 18:3-15.

MBTOC. 2010. Report of the Methyl Bromide Technical Options Committee (MBTOC) 2010 Assessment. Montreal Protocol on Substances that Deplete the Ozone Layer. United Nations Environment Programme (UNEP), Nairobi, Kenya.

Nicol, J. M., Turner, S. J., Coyne, D. L., Nijs, L. d., Hockland, S., and Maafi, Z. T. 2011. Current nematode threats to world agriculture. Pages 21-43 in: Genomics and Molecular Genetics of Plant-Nematode Interactions. J. Jones, ed. Springer Science+Business Media B.V., Dordrecht, The Netherlands.

Ohri, P., and Pannu, S. K. 2010. Effect of phenolic compounds on nematodesA review. J. Appl. Nat. Sci. 2:344-350.

Omwega, C. O., and Roberts, P. A. 1992. Inheritance of resistance to Meloidogyne spp. in common bean and the genetic basis of its sensitivity to temperature. Theor. Appl. Genet. 83:720-726.

Padgham, J. L., Duxbury, J. M., Mazid, A. M., Abawi, G. S., and Hossain, H. 2004. Yield loss caused by Meloidogyne graminicola on lowland rainfed rice in Bangladesh. J. Nematol. 36:42-48.

Pegard, A., Brizzard, G., Fazari, A., Soucaze, O., Abad, P., and Djian-Caporalino, C. 2005. Histological characterization of resistance to different root-knot nematode species related to phenolics accumulation in Capsicum annuиm. Phytopathology 95:158-165.

Petitot, A. S., Kyndt, T., Haidar, R., Dereeper, A., Collin, M., de Almeida Engler, J., Gheysen, G., and Fernandez, D. 2017. Transcriptomic and histological responses of African rice (Oryza glaberrima) to Meloidogyne graminicola provide new insights into root-knot nematode resistance in monocots. Ann. Bot. 119:885-899.

Plowright, R. A., Coyne, D. L., Nash, P., and Jones, M. P. 1999. Resistance to the rice nematodes Heterodera sacchari, Meloidogyne graminicola and $M$. incognita in Oryza glaberrima and $O$. glaberrima $\times O$. sativa interspecific hybrids. Nematology 1:745-751.

Prasad, J. S., Vijayakumar, C. H. M., Sankar, M., Varaprasad, K. S., Prasad, M. S., and Rao, Y. K. 2006. Root-knot nematode resistance in advanced back cross populations of rice developed for water stress conditions. Nematol. Mediterr. 34:3-8.

Rasband, W. S. 2014. ImageJ. Online publication. U.S. National Institutes of Health, Bethesda, MD. https://imagej.nih.gov/ij/

Rahman, M. L. 1990. Effect of different cropping sequences on root-knot nematode, Meloidogyne graminicola, and yield of deepwater rice. Nematol. Mediterr. 18:213-217.

R Development Core Team. 2009. The R Project for Statistical Computing. Online publication. Vienna. https://www.r-project.org/

Rebouillat, J., Dievart, A., Verdeil, J. L., Escoute, J., Giese, G., Breitler, J. C., Gantet, P., Espeout, S., Guiderdoni, E., and Périn, C. 2009. Molecular genetics of rice root development. Rice (N. Y.) 2:15-34. 
Reversat, G., Boyer, J., Sannier, C., and Bando-Baihuon, A. 1999. Use of a mixture of sand and water-absorbent synthetic polymer as substrate for the xenic culturing of plant-parasitic nematodes in the laboratory. Nematology 1:209-212.

Schneider, S. M. 1991. Penetration of susceptible and resistant tobacco cultivars by Meloidogyne juveniles. J. Nematol. 23:225-228.

Seck, P. A., Diagne, A., Mohanty, S., and Wopereis, M. C. S. 2012. Crops that feed the world 7: Rice. Food Sec. 4:7-24.

Sharma-Poudyal, D., Pokharel, R. R., Shrestha, S. M., and Khatri-Chhetri, G. B. 2004. Evaluation of common Nepalese rice cultivars against rice root knot nematode. Nepal Agric. Res. J. 5:33-36.

Siddiqui, I. A. 1971. Histopathogenesis of galls induced by Meloidogyne naasi in oat roots. Nematologica 17:237-242.

Silva, R. V., Oliveira, R. D. L., Ferreira, P. S., Ferreira, A. O., and Rodrigues, F. A. 2013. Defense responses to Meloidogyne exigua in resistant coffee cultivar and non-host plant. Trop. Plant Pathol. 38:114-121.

Slana, L. J., and Stavely, J. R. 1981. Identification of the chromosome carrying the factor for resistance to Meloidogyne incognita in tobacco. J. Nematol. 13:61-66.

Soriano, I. R., Schmit, V., Brar, D. S., Prot, J. C., and Reversat, G. 1999. Resistance to rice root-knot nematode Meloidogyne graminicola identified in Oryza longistaminata and O. glaberrima. Nematology 1:395-398.

Struble, F. B., Morrison, L. S., and Cordner, H. B. 1966. Inheritance of resistance to stem rot and root-knot nematode in sweetpotato. Phytopathology $56: 1217-1219$
Ventura, W., Watanabe, I., Castillo, M. B., and De la Cruz, A. 1981. Involvement of nematodes in the soil sickness of a dryland rice-based cropping system. Soil Sci. Plant Nutr. 27:305-315.

Villanueva, L. M., Prot, J.-C., and Matias, D. M. 1992. Plant parasitic nematodes associated with upland rice in the Philippines. J. Plant Prot. 9:143-149.

Vovlas, N., Rapoport, H. F., Jimenez Diaz, R. M., and Castillo, P. 2005. Differences in feeding sites induced by root-knot nematodes, Meloidogyne spp., in chickpea. Phytopathology 95:368-375.

Wang, X., Jacob, Y., Mastrantuono, S., Bazzano, J., Voisin, R., and Esmenjaud, D. 2004. Spectrum and inheritance of resistance to the root-knot nematode Meloidogyne hapla in Rosa multiflora and R. indica. Plant Breed. 123: 79-83.

Win, P. P., Kyi, P. P., Maung, Z. T. Z., and De Waele, D. 2013. Evaluation of the host response of lowland and upland rice varieties from Myanmar to the rice root-knot nematode Meloidogyne graminicola. Arch. Phytopathol. Plant Prot. 47:869-891.

Win, P. P., Kyi, P. P., Maung, Z. T. Z., Myint, Y. Y., and De Waele, D. 2015. Comparison of the damage potential and yield loss of the rice root-knot nematode, Meloidogyne graminicola, on lowland. Russ. J. Nematol. 23: 53-72.

Yik, C. P., and Birchfield, W. 1979. Host studies and reactions of cultivars to Meloidogyne graminicola. Phytopathology 69:497-499.

Yoshida, M. 1981. Breeding of peach rootstocks resistant to root-knot nematode. I. Root-knot nematode resistance in peaches and plums. Bull. Fruit Tree Res. Stn. 8:13-30. 